\title{
A NEW BAENID TURTLE FROM THE UPPER CRETACEOUS (MAASTRICHTIAN) HELL CREEK FORMATION OF NORTH DAKOTA AND A PRELIMINARY TAXONOMIC REVIEW OF CRETACEOUS BAENIDAE
}

\author{
TYLER R. LYSON ${ }^{*}, 1,2$ and WALTER G. JOYCE ${ }^{3,4}$ \\ ${ }^{1}$ Department of Geology and Geophysics, Yale University, 210 Whitney Avenue, New Haven, Connecticut 06511, U.S.A., \\ tyler.lyson@yale.edu; \\ ${ }^{2}$ Marmarth Research Foundation, Marmarth, North Dakota 58643, U.S.A.; \\ ${ }^{3}$ Institut für Geowissenschaften, University of Tübingen, Sigwartstraße 10, 72076, Tübingen, Germany, walter.g.joyce@gmail.com; \\ ${ }^{4}$ Peabody Museum of Natural History, Yale University, 170 Whitney Avenue, New Haven, Connecticut 06511, U.S.A.
}

\begin{abstract}
A fragmentary skull from the Hell Creek Formation (Maastrichtian) of southwestern North Dakota represents a new taxon of baenid turtle named herein Gamerabaena sonsalla. The length of the frontals, jugal contribution to the labial ridge, and convex contact between the vomer and the pterygoids indicate its affinities with the clade Palatobaena, but the new taxon clearly lacks the great posterior expansion of the triturating surface, complete absence of a lingual ridge, subrectangular skull, and wide angle between the maxillae that diagnose Palatobaena spp. A maximum parsimony analysis provides strong support for G. sonsalla as sister taxon to Palatobaena spp. Gamerabaena sonsalla has several morphological features that are intermediate between Plesiobaena antiqua and the morphologically disparate Palatobaena spp., including orbits that are oriented slightly dorsally and moderately expanded posterior triturating surfaces. Our phylogenetic analysis, combined with stratigraphic arguments, indicates that our skull-based taxon G. sonsalla could belong to the shell-based taxon "Baena" hayi. Similarly, the skull taxa Hayemys latifrons and Eubaena cephalica may be synonymous with the shell taxa Thescelus insiliens and "Baena" hatcheri, respectively.
\end{abstract}

\section{INTRODUCTION}

Baenidae (Cope, 1882) is an important clade of turtles that is phylogenetically placed within the exclusively North American and European clade Paracryptodira (sensu Gaffney, 1975; Joyce, 2007). The group includes the most common freshwater terrestrial turtles found in North American Cretaceous sedimentary rocks. The earliest baenids have been recovered from Lower Cretaceous sediments and no definitive baenids have yet been found outside of the western portion of North America. The clade appears to have diversified in the latest Cretaceous and went extinct in the Eocene (Gaffney, 1972; Hutchison and Archibald, 1986; Hutchison and Holroyd, 2003).

Baenidae, along with the Pleurosternidae (sensu Gaffney and Meylan, 1988), make up the Paracryptodira, a diverse clade of turtles that is now extinct. This clade is diagnosed by the presence of the internal carotid foramen located halfway between the contact of the basisphenoid and the pterygoid, as well as a small fenestra perilymphatica (Gaffney, 1979; Lipka et al., 2006; Joyce, 2007). Baenidae is the more speciose clade and is largely composed of the subclade Baenodda (sensu Brinkman, 2003), which includes Plesiobaena spp., Palatobaena spp., Boremys spp., Eubaena cephalica (Hay, 1904), Stygiochelys estesi Gaffney and Hiatt, 1971, Baena arenosa Leidy, 1870, and Chisternon undatum (Leidy, 1872). This clade is diagnosed by the presence of the fifth vertebral scute entering the shell margin, scalloped posterior edge of the shell, triangular anterior plastral lobe, small to absent dorsal exposure of the prefrontal, and small nasals. In addition, Baenidae includes more basal subclades that include Trinitichelys hiatti Gaffney, 1972, and Neurankylus eximius Lambe, 1902, as

\footnotetext{
${ }^{*}$ Corresponding author.
}

well as another clade that includes Hayemys latifrons Gaffney, 1972, and Thescelus insiliens Hay, 1908 (Lyson and Joyce, 2009).

Baenidae is among the most speciose groups of Late Cretaceous turtles (Gaffney, 1972; Hutchison and Holroyd, 2003). However, like other fossil turtle groups, most baenid taxa are based largely on fragmentary skulls or shells, and the alpha taxonomy of the group consequently suffers from extensive taxonomic conflict between named shell and skull taxa (Gaffney, 1972). This taxonomic conflict can result in an inflated number of named taxa, compared to the actual number of species. Hay (1908) recognized 21 species (to the exclusion of the non-baenid Naomichelys speciosa), most of which were known from isolated shells and skulls only. In his review of the group, Gaffney (1972) proposed a number of synonymies and nomina dubia that significantly reduced this taxonomic conflict. Although he reduced the number of recognized baenid species to 13 , only 4 were known at that point from skulls and shells, whereas 5 were known from skulls and 4 from shells only.

Since that seminal paper, there have been several changes to baenid alpha taxonomy. Several new baenid taxa have been described, taxon ranges have been extended, new material has been attributed to existing taxa, and taxon names have been resurrected. New taxa include Goleremys mckennai Hutchison, 2005, and two species of Palatobaena (Archibald and Hutchison, 1979; Lyson and Joyce, 2009). The first skull/shell associations were described for Boremys pulchra (Lambe, 1906), and N. eximius (Brinkman and Nicholls, 1991, 1993), and additional material was described for Plesiobaena antiqua (Brinkman, 2003). However, no new synonymies were proposed as a result of these descriptions. In fact, several taxa listed by Gaffney as nomina dubia have subsequently been resurrected, including "Baena" hayi Gilmore, 1916, "Baena" hatcheri, Hay, 1901, and "Baena" marshi Hay, 1904 (Hutchison and Holroyd, 2003), as well as "Baena" 
nodosa Gilmore, 1916, and "Baena" ornata, Gilmore, 1935 (now placed in the new genus Denaz inemys Lucas and Sullivan, 2006). Tomlinson (1997) reported on D. ornata (formerly “"Baena” ornata') from the Paleocene of Texas, but Tomlinson's identification was doubted by Lucas and Sullivan (2006), calling into question the putative stratigraphic range extension of that species. In addition to the description of several new specimens of Bo. pulchra, Brinkman and Nicholls (1991) explicitly regarded the shell taxon Boremys grandis Gilmore, 1935, as valid. Finally, Holroyd and Hutchison (2002) removed Compsemys victa Leidy, 1856, from Baenidae.

Lyson and Joyce (2009) incorporated much of this new material into their comprehensive phylogenetic analysis of Baenidae, which included 14 of the more complete baenid taxa. Yet, despite the great number of descriptions and phylogenetic studies, very little progress has been made since Gaffney (1972) in resolving the taxonomy of this group.

Herein we describe a new baenid taxon from the Hell Creek Formation (Maastrichtian) of southwestern North Dakota that is based on a fragmentary skull. Using phylogenetic and stratigraphic arguments, we then review the alpha taxonomy of Cretaceous baenids and tentatively propose a number of synonymies.

Institutional Abbreviations-ND, North Dakota Heritage Center, Bismarck, North Dakota; YPM, Yale Peabody Museum of Natural History, New Haven, Connecticut; UMMP, University of Michigan Museum of Paleontology, Ann Arbor, Michigan.

\section{SYSTEMATIC PALEONTOLOGY}

\section{TESTUDINES Linnaeus, 1758 \\ PARACRYPTODIRA Gaffney, 1975 BAENIDAE Cope, 1882 \\ BAENODDA Gaffney and Meylan, 1988 \\ GAMERABAENA SONSALLA, gen. et sp. nov.} (Figs. 1, 3B)

Type Specimen-ND 06-14.1, a well-preserved, incomplete skull without mandible (Fig. 1).

Type Locality and Age-Bucklin Township, Slope County, near Marmarth, North Dakota (qualified researchers can obtain more detailed locality information from the North Dakota Heritage Center); Hell Creek Formation (latest Maastrichtian), approximately $66 \mathrm{~m}$ below the Fort Union formational contact. The skull was found in a clay pebble conglomerate mixed with other microvertebrate fossils, including gar scales, trionychid shell fragments, crocodilian teeth, and 'fish' vertebrae. The rock is interpreted as a channel lag deposit.

Etymology - 'Gamera' refers to the fictional, fire-breathing turtle from the 1965 movie Gamera, in allusion to his fire breathing capabilities and the Hell Creek Formation, plus 'baena.' The specific epithet honors Donald and Margaret Sonsalla, on whose land the specimen was found and who graciously donated the fossil to the North Dakota Heritage Center; it is formed here explicitly as a noun in apposition, in accordance with Article 31.1 of the International Code of Zoological Nomenclature, Fourth Edition (International Commission on Zoological Nomenclature, 1999).

Diagnosis - Member of Baenidae based on: foramen posterius canalis carotici interni located between pterygoid halfway along basisphenoid; posteriorly expanded triturating surfaces with lingual ridge anteriorly only; well-developed pterygoid and basioccipital contact; relatively small prefrontal contribution to dorsal skull roof compared to other paracryptodires. Apomorphies of taxon that diagnose it from all other baenids: medially expanded dorsal prefrontal lappet, excluding frontal from orbit, prefrontal forming large portion of skull roof compared to other baenodds; laterally indented maxillae; notched frontals extending posteriorly well beyond orbital margin. In addition, several other char- acters diagnose G. sonsalla from other baenids: circular, dorsally oriented orbit, large medial contact of pterygoids, foramen palatinum posterius between pterygoid and palatine suture, jugal forms posterior portion of labial ridge, opisthotic does not participate in the formation of the stapedial foramen, and jugal excluded from orbital margin distinguish it from the clade of $C$. undatum, Ba. arenosa, and $S$. estesi; large, dorsally oriented orbit, short preorbital length, frontal exposure in external nares, jugal extends ventrally onto labial ridge of triturating surface, and lack of secondary palate differentiate it from the clade of E. cephalica and Boremys spp.; well-developed posterior expansion of triturating surface, well-developed medial contact of pterygoids, and dorsally oriented orbit distinguish it from $\mathrm{Pl}$. antiqua; weaker development of posterior expansion of triturating surface, acute angle formed between maxillae, presence of lingual ridge, medial contact of nasals, less swollen labial ridge, no palatine contribution to the triturating surface, and triangular skull shape differentiate it from Palatobaena spp.

\section{DESCRIPTION}

The holotype is well preserved with no distortion, but is incomplete. The damage consists of freshly broken surfaces caused by weathering prior to collection. The specimen was preserved in an oxidized sandstone matrix, which was removed with an air scribe, and consolidated with Vinac. The sutures are open and easily identifiable. Most of the right half of the skull is missing, as is a large posterior portion that includes most of the postorbitals, the quadrates, and the squamosals.

Because it is incomplete, the width and length of the skull cannot be measured, nor can the development of the upper temporal emargination be determined. The cheek region is deeply emarginated; it reaches at least as far dorsally as the level of the ventral margin of the orbit. The orbit is small, its diameter being less than the height of the maxilla below the orbit. The orbit is oriented slightly dorsally, like those found in Palatobaena spp. The orbit is also 'inset' into the dorsal portion of the maxilla (i.e., the ventrolateral aspect of the orbit is delimited by a distinct ridge formed by the maxilla). Such inset orbits are also found in Plesiobaena putorius Gaffney, 1972, and Palatobaena spp. The distance between the orbits is large. This distance is significantly larger than that of either Stygiochelys estesi or Eubaena cephal$i c a$, but not as large as that found in Palatobaena spp. As in E. cephalica, but not as pronounced, there is a constriction of the maxilla just anterior to the orbits, resulting in a laterally compressed snout in ventral view. No scale sulci on the dorsal skull roof are present (Fig. 1).

The length of the parietals is approximately equal to their maximum combined width. The parietals combined form a wedge that protrudes between the frontals. As such, the lateral part of the frontal-parietal suture terminates well behind the orbit, whereas the medial part protrudes as far anteriorly as the orbit. The parietal-postorbital suture is strongly curved outwards, thus reducing the size of the postorbital. The processus inferior parietalis contributes to the formation of the lateral wall of the braincase (Fig. 1).

The frontals are very large and extend further posteriorly than in any other baenodd (Gaffney, 1982). Frontal length is more than double frontal width. Because the parietals form a wedge in between the frontals, the lateral length of the frontals is much longer than their medial length, as in Palatobaena spp., particularly Palatobaena cohen Lyson and Joyce, 2009. The frontals contact the nasals anteriorly, the maxillae, the prefrontals, and the postorbitals laterally, the parietals posteriorly, and one another medially. Small anterolateral processes protrude anteriorly into the external narial opening and separate the nasals from the maxillae. The nasals are relatively large and form a major portion of the snout region and the dorsal portion of the rim of the 


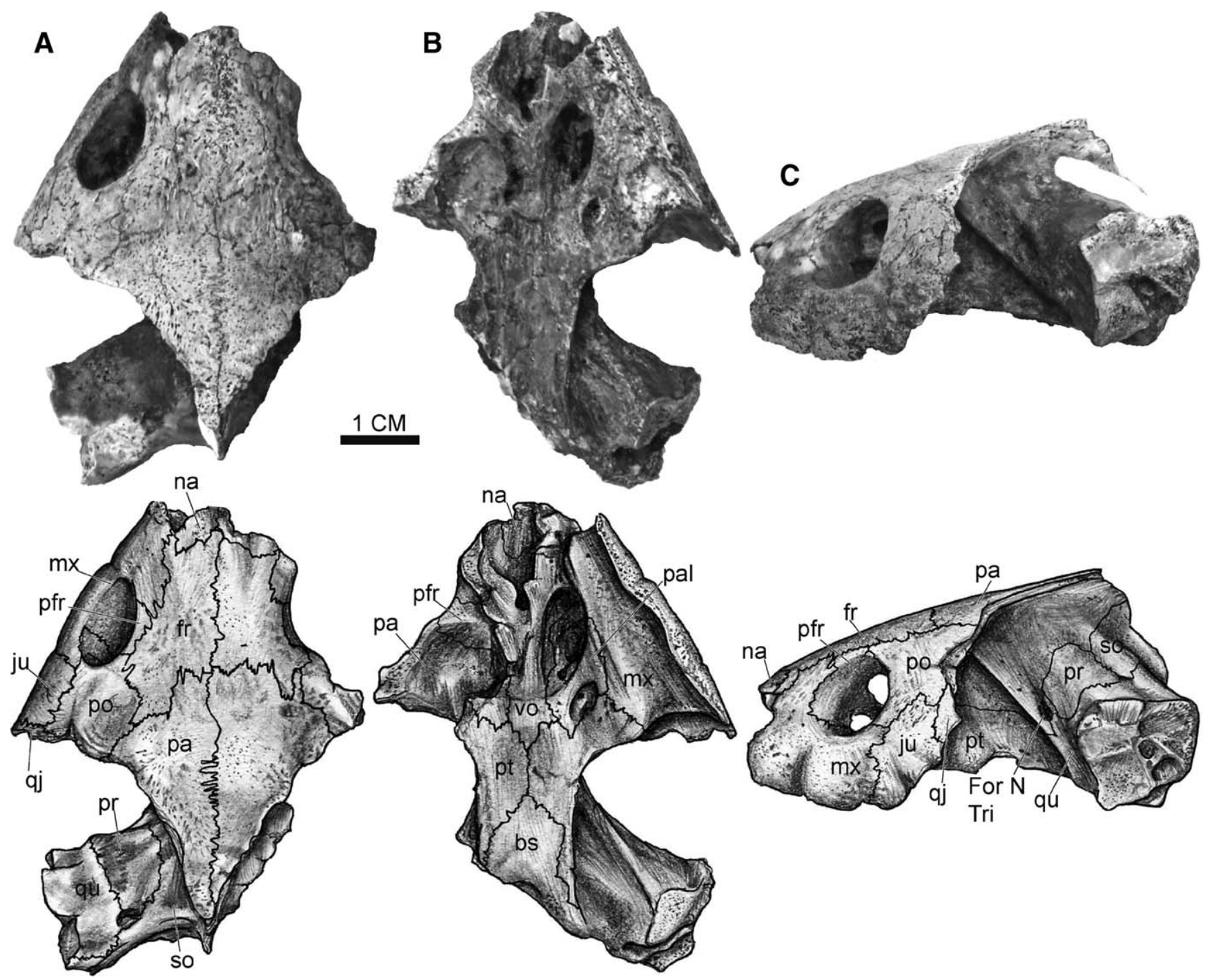

FIGURE 1. Photographs (top) and illustrations (bottom) of the holotype (ND06-14.1) of Gamerabaena sonsalla. A, dorsal, B, palatal, and C, lateral views. Abbreviations: bs, basisphenoid; For N Tri, foramen nervi trigemini; fr, frontal; ju, jugal; na, nasal; mx, maxilla; pa, parietal; pal, palatine; pfr, prefrontal; po, postorbital; pr, prootic; pt, pterygoid; qu, quadrate; qj, quadratojugal; so, supraoccipital; vo, vomer.

external narial opening. The exposure of the prefrontal on the skull roof is well developed relative to other baenodds. This large prefrontal exposure on the skull roof prevents the frontal from entering the orbital margin. The maxilla forms the lateral part of the face. In ventral view, a clear indentation is visible on the maxilla just below the anterior orbital margin, which gives the skull a distinct snout. The labial ridge of the triturating surface is swollen, as in Palatobaena spp. and S. estesi. The posterior portion of the triturating surface is a wide, flat area, the width being equal to or greater than the depth of the labial ridge of the maxilla. The medial edge of the triturating surface is broken, but is partially formed by the palatal bones. A lingual ridge is present on the anterior portion of the triturating surface similar to other baenodds except for Palatobaena spp. and E. cephalica (Fig. 1).

The jugal is large and is excluded from the orbital margin by a flange of the maxilla, which extends dorsally behind the orbit to connect with a flange of the postorbital that extends ventrally behind the orbit. A similar condition of the jugal is found in $E$. cephalica, Pl. antiqua, and Boremys pulchra. The jugal extends dorsally into the postorbital, further reducing the postorbital in size. A slender process of the jugal extends ventrally and forms the most posterior portion of the labial ridge as in Pl. antiqua and Palatobaena spp. The jugal has a relatively large exposure on the ventral rim of the cheek (Fig. 1).

The medial contact of the pterygoids is well developed as in other baenodds except $S$. estesi and $C$. undatum (Gaffney, 1982). The basisphenoid is only partially preserved, but from what is preserved it is apparent that it is pentagonal in ventral view and that the foramen posterius canalis carotici interni is located midway along the sides of this bone in the suture with the pterygoid. The posterior region of the palate, which is formed by the basisphenoid and posterior pterygoid flanges, is very slender. The vomer extends posteriorly between the anterior portions of the pterygoids and partly separates them. The palatines are small hourglass-shaped bones. The foramen palatinum posterius is located between the palatine and the pterygoid (Fig. 1). Unlike Palatobaena spp. and $\mathrm{Pl}$. antiqua, no portion of the palatine laps onto the triturating surface. The foramen nervi trigemini is an 


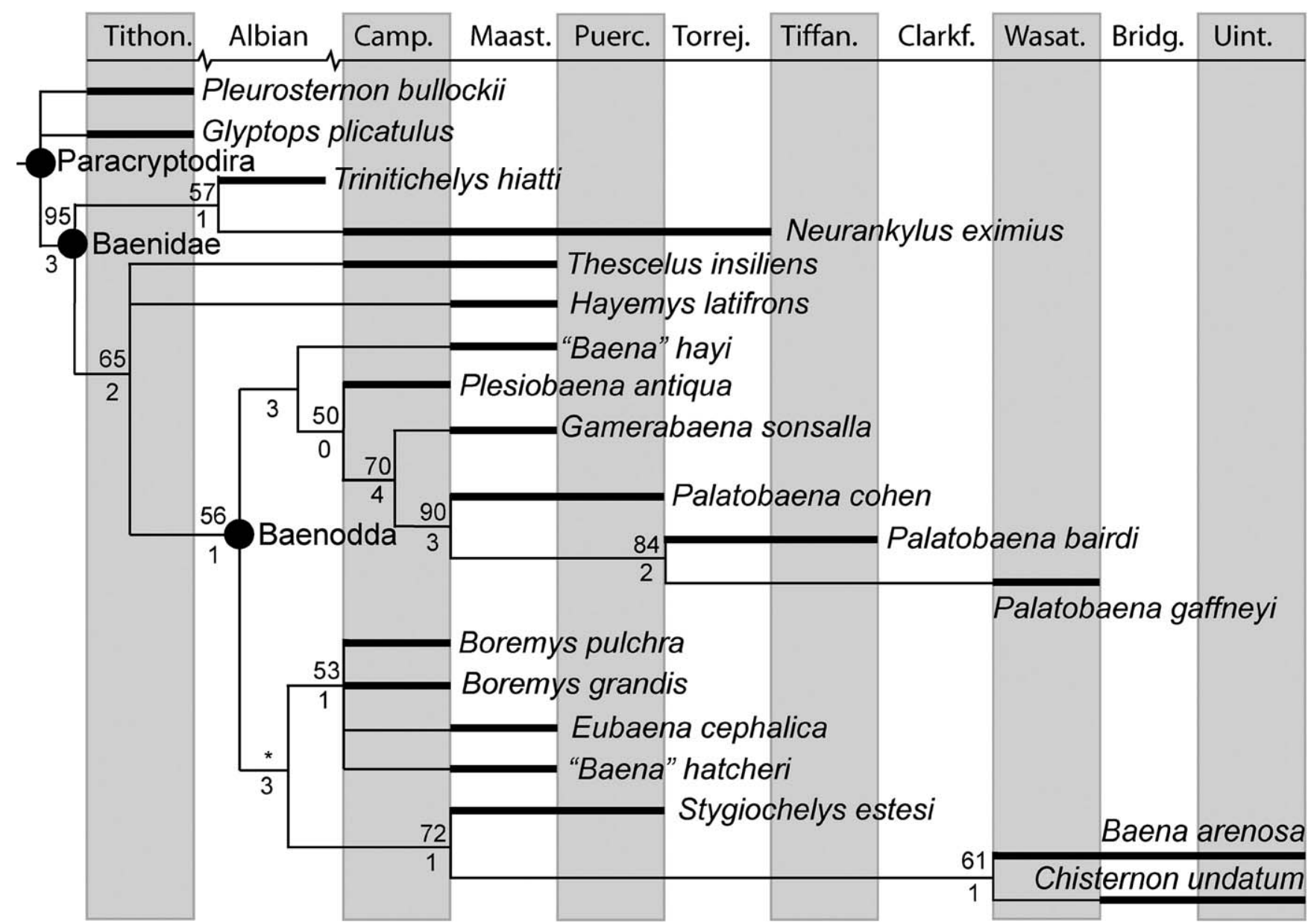

FIGURE 2. Paracryptodiran cladogram mapped against the stratigraphic range from which each taxon has been reported (bold lines). Bootstrap (top) and Bremer (bottom) support values are provided for each clade. The asterisk $\left(^{*}\right)$ indicates a bootstrap value under 50.

elongate oval and is mostly enclosed by the parietals, as in $P l$. antiqua (Brinkman, 2003). There is no sign of an epipterygoid.

The processus trochlearis oticus is subcircular in cross-section. The supraoccipital, the quadrate, and the prootic form the stapedial foramen. The quadrate contacts the supraoccipital, thereby excluding the opisthotic from the stapedial foramen.

\section{PHYLOGENETIC ANALYSIS}

A phylogenetic analysis was performed using the matrix from Lyson and Joyce (2009). In addition, 17 characters were added to the analysis and are listed in Appendix 1. Four ingroup taxa were added to the analysis: Gamerabaena sonsalla, Thescelus insiliens, "Baena" hatcheri, and "Baena" hayi. The skull-based taxon Goleremys mckennai was removed from the analysis, because it behaves like a wildcard taxon (Nixon and Wheeler, 1992). A total of 71 osteological characters and 19 taxa, including 17 ingroup taxa, were analyzed. Eight characters were considered to represent morphoclines and were ordered $(7,14,16,18,28,33,36$, and 70). The remaining characters were run unordered and all characters were left unweighted. Missing data were scored as '?'. The complete matrix forms Appendix 2. A maximum parsimony analysis was performed on the dataset using PAUP 4.0b10 (Swofford, 2003). Glyptops plicatulus (Cope, 1877) and Pleurosternon bullocki Owen, 1842, were specified as the outgroup taxa and a branch-and-bound search was used with minimum branch lengths set to collapse. Support for each node was measured by calculating Bremer support values (Bremer, 1994) and bootstrap frequencies (Felsenstein, 1985), with 10,000 bootstrap replicates and 100 random sequence addition replicates. Bootstrap frequencies greater than $70 \%$ are considered strong support (Hillis and Bull, 1993).

The parsimony analysis resulted in two most-parsimonious trees, each with a tree length of 149 steps, consistency index of 0.56 , retention index of 0.69 , and rescaled consistency index of 0.39 . Figure 2 is the strict consensus of the two trees, and shows that $G$. sonsalla is sister taxon to the clade of Palatobaena spp. The remainder of the topology is very similar to the results obtained by Lyson and Joyce (2009). Both our results and those of Lyson and Joyce (2009) provide support for S. estesi as sister taxon to the clade of Baena arenosa and Chisternon undatum (bootstrap $=72 \%$; Bremer support $=1$ ). This analysis provides weak support for Pl. antiqua as sister taxon to the clade of $G$. sonsalla and the Palatobaena spp. (bootstrap frequency $=50 \%$ ), a relationship that is diagnosed by two synapomorphies: large jugal that contributes to the labial margin (19-1) and convex vomer and pterygoid contact (26-1). Gamerabaena sonsalla as sister taxon to the clade of Palatobaena spp. is relatively strong (bootstrap frequency $=70 \%$; Bremer support $=4$ ), and is supported by the following synapomorphies: dorsally oriented orbits (6-1), swollen maxillae (11-1), length between orbit and cheek emargination is equal to the diameter of the orbit (67-1), notched frontal-parietal 
A
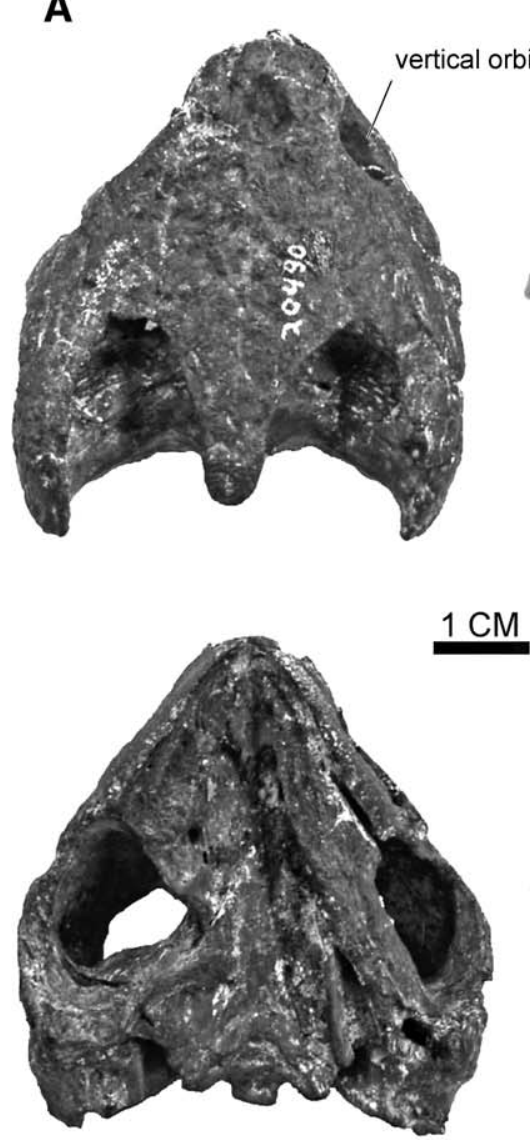

B

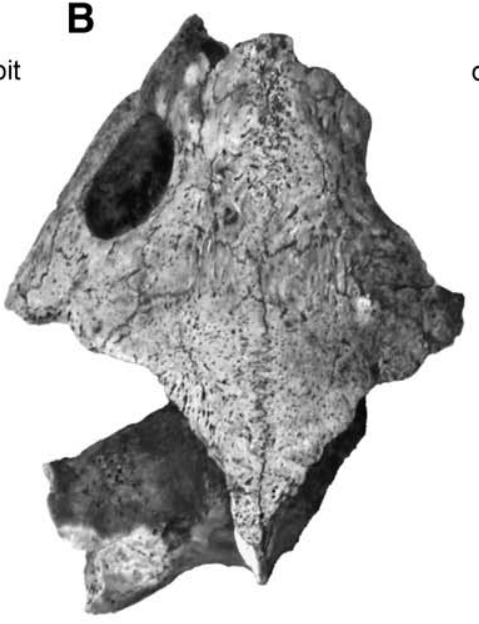

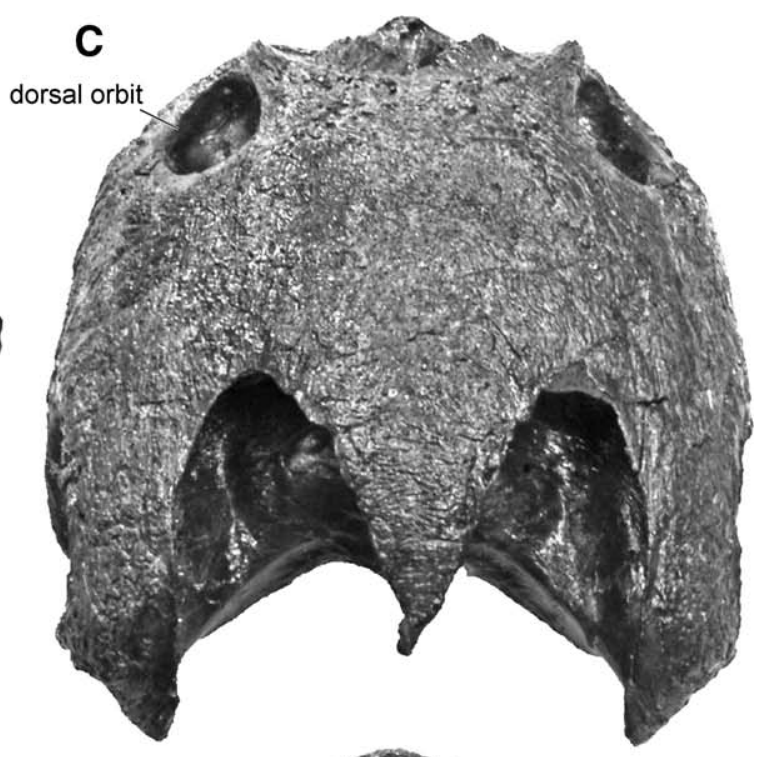
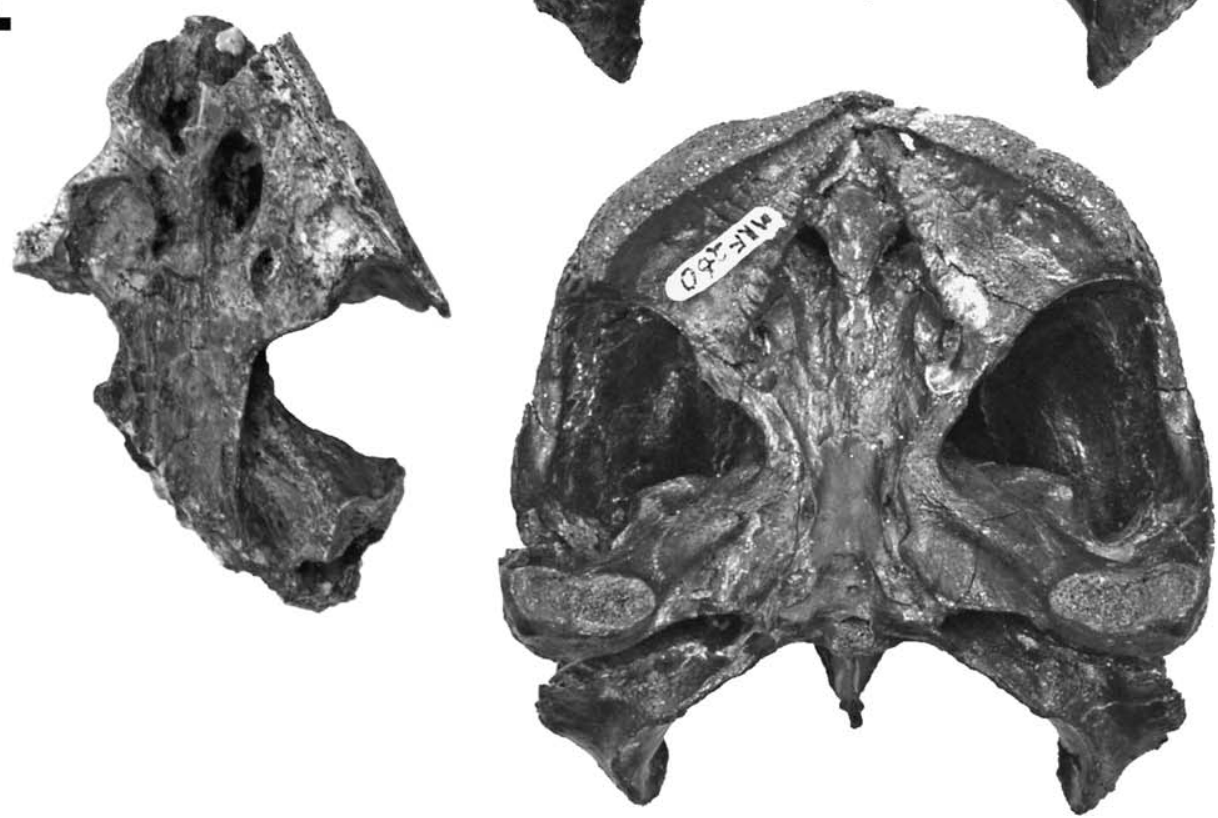

FIGURE 3. Dorsal (top) and ventral (bottom) views of A, Plesiobaena sp., UMMP V20490, B, Gamerabaena sonsalla, ND06-14.1, and C, and Palatobaena cohen, YPM 57498, illustrating the intermediate morphology of G. sonsalla. The orientation of the orbits and posterior expansion of the triturating surface are the most notable intermediate characters.

suture (68-1), and orbits that are inset in the maxillae (71-1). The analysis provides strong support for the clade of Palatobaena spp. (bootstrap frequency $=90 \%$; Bremer support $=3$ ) (Fig. 2).

\section{DISCUSSION}

Our phylogenetic analysis indicates that Gamerabaena sonsalla forms a clade with Plesiobaena antiqua and Palatobaena spp. According to the phylogenetic analysis, $G$. sonsalla is more closely related to Palatobaena spp. than to $P$ l. antiqua, providing a link between the morphologically disparate skulls of Palatobaena spp. and the more generalized baenid skull seen in other baenodds (Fig. 3). In particular, the triturating surface is intermediate between the slightly expanded surface found in Pl. antiqua and the greatly expanded surface found in Palatobaena spp. In addition, the orbits of $G$. sonsalla are oriented slightly dorsally and are inset in the maxilla, a position that is again intermediate between the vertically oriented orbits with no inset found in Pl. antiqua and the dorsally oriented and inset orbits found in Palatobaena spp. (Fig. 3). Gamerabaena sonsalla thus represents an intermediate morphology between the presumably omnivorous $\mathrm{Pl}$. antiqua and the molluscivorous Palatobaena spp. (Archibald and Hutchison, 1986).

The description of yet another skull-based baenid taxon increases the number of valid baenid taxa known from the Maastrichtian and adds to the parataxonomic conflict found within Baenidae. This parataxonomic conflict is particularly evident in the latest Cretaceous (Campanian and Maastrichtian), where 14 taxa are currently recognized. The Campanian has four shellbased taxa, no skull-based taxa, and three skull- and shell-based taxa. The Maastrichtian has three shell-based taxa (one of which is also found in the Campanian), three skull-based taxa, and four skull- and shell-based taxa (Fig. 4). The ultimate test of synonymy is provided by the acquisition of firm skull-and-shell associations (e.g., Brinkman and Nicholls, 1991, 1993; Brinkman, 2003; Lyson and Joyce, 2009), yet, surprisingly, no new synonymies have yet 


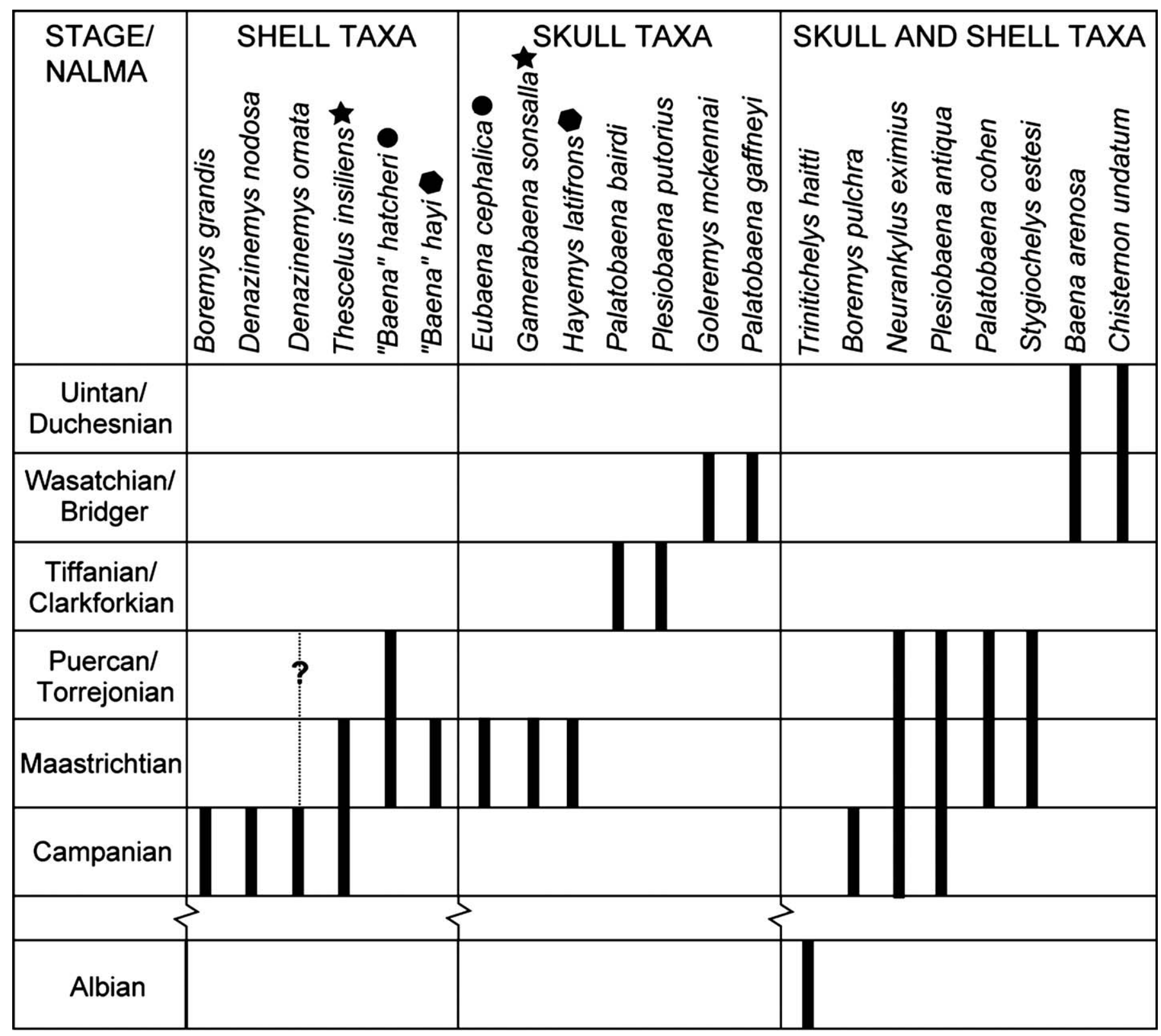

FIGURE 4. Revised alpha taxonomy of baenid turtles mapped against the stratigraphic ranges (bold lines) reported for each taxon. The dotted line indicates a range extension based on questionable species identification. Symbols represent proposed synonymies between skull-based and shelledbased taxa. Abbreviation: NALMA, North American Land Mammal Age.

to be proposed based on such new finds since Gaffney (1972). However, due to an increased understanding of morphological variation found within Baenidae (pers. observ. by the authors of a large sample of baenids from a single quarry in North Dakota; see Lyson and Joyce, 2009) and better sampling of characters and taxa, stratigraphic and phylogenetic considerations allow for some reassessments and tentative synonymies.

Taxonomic Considerations - "Baena" marshi is based on a highly fragmentary shell from the Lance Formation that was originally diagnosed by its plastral lobe dimensions and the thickness of its carapace (Hay, 1904, 1908). Although both papers are not explicit, Gaffney (1972) appears to dismiss this taxon as a nomen dubium whereas Holroyd and Hutchison (2002) regard it to be valid. Our personal observations of the holotype, YPM 299 , reveal that the thickness of the carapace is comparable to that found in other baenodds and that the lobes of "Ba." marsh $i$ are not unique as well, and we are unable to identify any autapomorphies. Finally, if this taxon were to be placed in our phylogenetic analysis, all but eight characters would have to be scored as unknown. The holotype thus lacks diagnostic characters and we herein consider this taxon a nomen dubium. At best, we feel that the holotype can be referred to Baenodda.

The type materials of both Thescelus insiliens and Hayemys latifrons are from the Hell Creek Formation, but the former taxon is based on a shell, whereas the latter is based on a skull. Gaffney (1972), using phylogenetic and stratigraphic arguments comparable to those that we are using herein, speculated that $N$. eximius and Th. insiliens represent the shells of $H$. latifrons and $\mathrm{Pa}$. cohen (i.e., Cretaceous material formerly referred to as Pa. bairdi; see Lyson and Joyce, 2009), respectively. However, 
additional material has since shown that $N$. eximius and $P a$. cohen possess a unique skull and shell (Brinkman and Nicholls, 1993; Lyson and Joyce, 2009), respectively, which objectively overturned these speculations. Interestingly, our phylogenetic analysis (using cranial characters) confirms Gaffney's (1972) original assessment that the skull taxon $H$. latifrons is phylogenetically derived relative to $T r$. hiatti but basal to Baenodda (Fig. 2). The addition of the skull of $N$. eximius reveals that $H$. latifrons is more derived than that taxon as well. Conversely, our dense sampling of shell characters firmly placed $T h$. insiliens in a polytomy with $H$. latifrons (Fig. 2). Given that both taxa are based on material from the Hell Creek Formation, we suspect that these two taxa may be synonymous. Further material may be able to test this idea and, should it come to pass, Th. insiliens (Hay, 1908) would be the senior synonym and H. latifrons the junior synonym (Gaffney, 1972).

Among named Maastrichtian shell taxa, only two now remain that might represent the shells of G. sonsalla: "Baena" hatcheri and "Baena" hayi. "Baena" hatcheri is based on a well-preserved shell that exhibits a number of affinities otherwise seen in Boremys spp., $S$. estesi, Ba. arenosa, and $C$. undatum, including the presence of a nuchal scute, divided cervical scutes, and anterior suprapleural scutes, indicating this taxon belongs to the clade formed by these taxa. Whereas the shell attributed to E. cephalica (Archibald, 1977) is too fragmentary to determine whether or not any of these characters are present, its phylogenetic placement suggests that they were present in this taxon. The phylogenetic analysis places "Ba." hatcheri in a polytomy with E. cephalica and Boremys spp. Given this scenario, the non-overlapping skeletons of E. cephalica and "Ba." hatcheri, their similar geographic distributions, and their presence in the latest Maastrichtian, these two species are likely synonymous. The synonymy of these taxa would result in the name Eubaena hatcheri; the phylogenetic placement of the taxon indicates it is more closely related to Eubaena than to $B a$. arenosa, and the species epithet hatcheri (Hay, 1901) has seniority over cephalica (Hay, 1904).

The overall morphology of "Ba." hayi, in contrast, is similar to that of members of the clade of Plesiobaena spp., Palatobaena spp., and G. sonsalla, of which shells are known for Pl. antiqua and $P a$. cohen. In particular, these taxa share the following symplesiomorphies: an undivided cervical scale, four pleural scutes, small extragular scales, and vertebral scutes that are wider than long (Lyson and Joyce, 2009). However, the first vertebral of "Ba." hayi narrows anteriorly as does that of $P a$. cohen, which is interpreted herein as a synapomorphy. "Baena" hayi differs from $P a$. cohen in having a better developed medial extragular contact, well-developed posterior scallops, and by lacking a strong nuchal projection. The phylogenetic analysis places "Ba." hayi as sister taxon to the clade of $\mathrm{Pl}$. antiqua, G. sonsalla, and Palatobaena spp. Thus, given "Ba." hayi's phylogenetic placement, the nonoverlapping skeletal elements with G. sonsalla, and their equivalent stratigraphy, these species may be synonymous as well. Because the former taxon is not closely related to the genus type species $B a$. arenosa, it would be transferred to the genus Gamerabaena and $G$. sonsalla would become its junior synonym, should the synonymy come to pass.

Figure 4 summarizes our revised alpha taxonomy for Baenidae. As discussed above, several lines of evidence suggest that $H$. latifrons, "Ba." hatcheri, and "Ba." hayi may be synonymous with T. insiliens, E. cephalica, and G. sonsalla, respectively. For now, however, each taxon by itself is diagnostic and must be regarded as valid until definite skull-and-shell associations are found. Interestingly, if our speculations are eventually supported by new finds, the number of valid baenid taxa from the Maastrichtian would decrease from 10 to 7 , which is comparable to the diversity of Campanian baenids. The apparent rise in baenid diversity towards the end of the Cretaceous would thus be shown to be an artifact of taxonomy rather than elevated levels of speciation.

\section{ACKNOWLEDGMENTS}

We wish to thank the landowners, D. and M. Sonsalla, for donating the specimen to the North Dakota Heritage Center. Jim Parham, S. Modesto, and an anonymous reviewer made suggestions that significantly improved the manuscript. William Pinder assisted in the preparation of the specimens and J. Lyson and E. Schachner drew the figures. Funds for the preparation and illustrations of the specimen were provided by NSF grant IBN0316025 to S. Gilbert. Additional funding for this project was provided by a National Science Foundation Graduate Research Fellowship to T.R.L. Much of the work for this paper was completed while T.R.L. was working with S. Gilbert at Swarthmore College.

\section{LITERATURE CITED}

Archibald, J. D. 1977. Fossil Mammalia and Testudines of the Hell Creek Formation, and the geology of the Tullock and Hell Creek formations, Garfield County. Ph.D. dissertation, University of California, Berkeley, California, 694 pp.

Archibald, J. D., and J. H. Hutchison. 1979. Revision of the genus Palatobaena (Testudines, Baenidae), with the description of a new species. Postilla 177:1-19.

Bremer, K. 1994. Branch support and tree stability. Cladistics 10:295-304. Brinkman, D. B. 2003. Anatomy and systematics of Plesiobaena antiqua (Testudines: Baenidae) from the mid-Campanian Judith River Group of Alberta, Canada. Journal of Vertebrate Paleontology 23:146-155.

Brinkman, D. B., and E. L. Nicholls. 1991. Anatomy and relationships of the turtle Boremys pulchra (Testudines: Baenidae). Journal of Vertebrate Paleontology 11:302-315.

Brinkman, D. B., and E. L. Nicholls. 1993. The skull of Neurankylus eximius (Testudines: Baenidae) and a reinterpretation of the relationships of this taxon. Journal of Vertebrate Paleontology 13:273-281.

Cope, E. D. 1877. On reptilian remains from the Dakota beds of Colorado. Proceedings of the American Philosophical Society 17:193-196.

Cope, E. D. 1882. Contributions to the history of the Vertebrata of the Lower Eocene of Wyoming and New Mexico, made during 1881. Proceedings of the American Philosophical Society 20:139-197.

Felsenstein, J. 1985. Confidence limits on phylogenies: an approach using the bootstrap. Evolution 39:783-791.

Gaffney, E. S. 1972. The systematics of the North American family Baenidae (Reptilia, Cryptodira). Bulletin of the American Museum of Natural History 147:241-320.

Gaffney, E. S. 1975. A phylogeny and classification of the higher categories of turtles. Bulletin of the American Museum of Natural History 155:387-436.

Gaffney, E. S. 1979. The Jurassic turtles of North America. Bulletin of the American Museum of Natural History 162:93-135.

Gaffney, E. S. 1982. Cranial morphology of the baenid turtles. American Museum Novitates 2737:1-22.

Gaffney, E. S., and R. Hiatt. 1971. A new baenid turtle from the Upper Cretaceous of Montana. American Museum Novitates 2443:1-9

Gaffney, E. S., and P. A. Meylan. 1988. A phylogeny of turtles; pp. 157-291 in M. J. Benton (ed.), The Phylogeny and Classification of the Tetrapods, Volume 1. Amphibians, Reptiles, Birds. Systematics Association Special Volume No 35A, Clarendon Press, Oxford, U.K.

Gilmore, C. W. 1916. Description of two new species of fossil turtles, from the Lance Formation of Wyoming. Proceedings of the U.S. National Museum 50:641-646.

Gilmore, C. W. 1935. On the Reptilia of the Kirtland Formation of New Mexico, with descriptions of new species of fossil turtles. Proceedings of the U.S. National Museum 83:159-188.

Hay, O. P. 1901. Description of a new species of Baena (B. hatcheri) from the Laramie beds of Wyoming. Annals of Carnegie Museum $1: 325-326$

Hay, O. P. 1904. On some fossil turtles belonging to the Marsh collection in Yale University Museum. American Journal of Science 18:261-276.

Hay, O. P. 1905. On two species of turtles from the Judith River beds of Montana. Annals of Carnegie Museum 3:178-182. 
Hay, O. P. 1908. The fossil turtles of North America. Carnegie Institute of Washington, Publication 75:1-568.

Hillis, D. M., and J. J. Bull. 1993. An empirical test of bootstrapping as a method for assessing confidence in phylogenetic analysis. Systematic Biology 42:182-192.

Holroyd, P., and J. H. Hutchison. 2002. Patterns of geographic variation in latest Cretaceous vertebrates: evidence from the turtle component; pp. 177-190 in J. H. Hartman, K. R. Johnson, and D. J. Nichols (eds.), The Hell Creek Formation and Cretaceous-Tertiary Boundary in the Great Plains: An Integrated Continental Record of the End of the Cretaceous. Geological Society of America, Special Paper 361.

Hutchison, J. H. 2005. A new eubaenine, Goleremys mckennai, gen. et sp. n., (Baenidae: Testudines) from the Paleocene of California. Bulletin of the Carnegie Museum of Natural History 36:91-96.

Hutchison, J. H., and J. D. Archibald. 1986. Diversity of turtles across the Cretaceous/Tertiary Boundary in northeastern Montana. Palaeogeography, Palaeoclimatology, Palaeoecology 55:1-22.

Hutchison, J. H., and P. A. Holroyd. 2003. Late Cretaceous and early Paleocene turtles of the Denver Basin, Colorado. Rocky Mountain Geology 38:121-142.

International Commission on Zoological Nomenclature. 1999. International Code of Zoological Nomenclature. Fourth Edition. International Trust for Zoological Nomenclature, London, $306 \mathrm{pp}$.

Joyce, W. G. 2007. Phylogenetic relationships of Mesozoic turtles. Bulletin of the Peabody Museum of Natural History 48:3-102.

Lambe, L. M. 1902. On the Vertebrata of the mid-Cretaceous of the Northwest Territory. Contributions to Canadian Paleontology 3:25-81.

Lambe, L M. 1906. Description of new species of Testudo and Baena with remarks on some Cretaceous forms. Ottawa Naturalist 10:187-198.

Leidy, J. 1856. Notices of extinct Vertebrata discovered by Dr. F. V. Hayden, during the expedition to the Sioux country under command of Lieut. G. K. Warren. Proceedings of the Academy of Natural Sciences of Philadelphia 8:311-312.

Leidy, J. 1870. [Description of Emys jeanesi n. sp., Emys haydeni n. sp., Baena arenosa n. g. n. sp., and Saniwa ensidens n. g. n. sp.] Proceedings of the Academy of Natural Sciences of Philadelphia 1870:123-124.

Leidy, J. 1871. Remarks on fossil vertebrates from Wyoming. American Journal of Science 2:372-373.

Leidy, J. 1872. On a new genus of extinct turtles. Proceedings of the Academy of Natural Sciences of Philadelphia 1872:162.

Linnaeus, C. 1758. Systema Naturae, Volume 1. Tenth Edition. Laurentius Salvius, Holmia.

Lipka, T. R., F. Therrien, D. B. Weishampel, H. A. Jamniczky, W. G. Joyce, M. W. Colbert, and D. B. Brinkman. 2006. A new turtle from the Arundel Clay facies (Potomac Formation, Early Cretaceous) of Maryland, U.S.A. Journal of Vertebrate Paleontology 26:300-307.

Lucas, S. G., and R. M. Sullivan. 2006. Denazinemys, a new name for some late Cretaceous turtles from the Upper Cretaceous of the San Juan Basin, New Mexico; pp. 223-227 in S. G. Lucas and R. M. Sullivan (eds.), Late Cretaceous Vertebrates from the Western Interior. New Mexico Museum of Natural History and Science Bulletin 35.

Lyson, T. R., and W. G. Joyce. 2009. A new species of Palatobaena (Testudines: Baenidae) and a maximum parsimony and Bayesian phylogenetic analysis of Baenidae. Journal of Paleontology 83:457-470.

Nixon, K. C., and Q. D. Wheeler. 1992. Extinction and the origin of species; pp. 119-143 in M. J. Novacek and Q. D. Wheeler (eds.), Extinction and Phylogeny. Columbia University Press, New York.

Owen, R. 1842. Report on British fossil reptiles. Part II. Report of the British Association for the Advancement of Science 11:60-204.

Swofford, D. L. 2003. PAUP*: Phylogenetic Analysis Using Parsimony (*and Other Methods). Version 4.0b10. Sinauer Associates, Sunderland, Massachusetts.

Tomlinson, S. L. 1997. Late Cretaceous and early Tertiary turtles from the Big Bend region, Brewster County, Texas. Ph.D. dissertation, Texas Tech University, Lubbock, Texas, 194 pp.

Submitted February 9, 2009; accepted June 12, 2009.
APPENDIX 1. Descriptions of characters not included in Lyson and Joyce (2009).

(55) Shape of vertebral scute 1: hexagonal, anterior margin as wide as posterior margin (0); hexagonal, anterior margin significantly narrower than posterior margin (1).

(56) Shape of xiphiplastron and hypoplastron suture in ventral view: straight (0); Z-shaped (1).

(57) Pygal notch: absent (0); present (1).

(58) Anterior scallops on carapace: absent (0); weakly scalloped anterior quarter of carapace (1).

(59) Shape of vertebral scute 2: hexagonal (0); square or rectangular (1).

(60) Shape of sulcus between and vertebral scutes 4 and 5: curved anteriorly (0); straight (1).

(61) Deep circumnarial sulcus: absent (0); present (1).

(62) Shape of processus externus pterygoideus: curved flange that comes to a point laterally (0); greatly reduced, rounded (1).

(63) Angle between maxillae: acute angle (0); obtuse angle (1).

(64) Jugal thickening or tubercle: jugal thins ventrally (0); jugal thickens or has rounded tubercle (1).

(65) Vertical indentation in maxilla anterior to orbit: absent (0); present (1).

(66) Shape of posterior portion of basioccipital tubercles in posterior view: blocky (0); sagitally horizontal tubercles present (1).

(67) Distance between posterior margin of orbit and anterior portion of cheek emargination: approximately one-half diameter of the orbit (0); equal to diameter of orbit (1).

(68) Shape of parietal and frontal suture: slightly curved or straight (0); greatly curved or notched (1).

(69) Size of mandibular condyle: small (0); large (1).

(70) Supraoccipital exposure on skull roof: absent (0); small exposure (1); large exposure (2).

(71) Orbit inset into maxilla: absent, floor of orbit flat (0); present, orbit appears 'sunk' into dorsal portion of maxilla due to formation of narrow ridge formed by maxilla along the ventral rim of orbit (1).

APPENDIX 2. Character-taxon matrix for the phylogenetic analysis performed in this study. Missing data are coded as '?' Polymorphic character states are in parentheses. Inapplicable data are coded as ' - '.

Pleurosternon bullocki

$0000000000 \quad 00000000000000000000$ 00?0?00000

0000000000 0???000000 000000--000 0

Glyptops plicatulus

$01000000000000000000000000000000 ? 0000000$

0000000000 0???000000 000000--000 0

Trinitichelys hiatti

0000001000000100010000001002 ?? 21??????00

?00000?000 100000?00? 0000000000 0

Neurankylus exemius

?0???????? ???0100??? 010?????11 21???10000

00000000001000000000 0000?0????

Hayemys latifrons

100??0??0? 0000021100 100??0121? 20????????

????????? ?????????? 000000000? 0

Plesiobaena antiqua

1000001111010110101010001101111001011110

1000000011111101101100000000010

Boremys pulchra

111000?10? 0101101?00 1000?00211 1010031101

$101(01) 111100101011111100000000010$ 
Boremys grandis

?????????? ?????????? ????????? ???? 31101

10101111001010111111 ????????? ?

Eubaena cephalica

111010210001011210001000200211 10????????

?????????? ?????????? 00000011010

Palatobaena cohen

$200001211111220111101000110211 \quad 1001111110$

?000000011 11?111?011 11110111111

Palatobaena bairdi

200001211111221112101110110211 10011?????

????????? ????????? 11110011121

Palatobaena gaffneyi

200011211111221111101110110111 10???????

?????????? ?????????? 11110011121

Stygiochelys estesi

100100111011121011001001001111 11????????

??1111?0?0 ?11?1??01? 0000001001 0
Baena arenosa

$110100111001 ? 210120101110002111121011100$

$111101000011111 ? 101100000000000$

Chisternon undatum

1101001110011210120100110011111120011101

1011110000111111101100000001010

Gamerabaena sonsalla

?000011110 111102101? ??1??10211 10???????

?????????? ?????0???? 00001?11?? 1

Thescelus insiliens

?????????? ?????????? ?????????? ?????00000

$0010000001111100 ? 011$ ????????? ?

"Baena" hayi

?????????? ?????????? ?????????? ?????2111?

?010000001 1111111011 ????????? ?

"Baena" hatcheri

?????????? ?????????? ????????? ? ??? 21100

10111100011010111011 ???????? ? 